\title{
Sero-prevalence of brucellosis in cattle at Dhamar governorate, Yemen
}

\author{
Ahmed Yahya Al-Qudari ${ }^{1, *}$, Maged Ahmed Al-Garadi ${ }^{2}$, Fawaz Ali Al-Monifi ${ }^{3}$ \\ ${ }^{1}$ Assistant Professor, Dept. of Veterinary Medicine, Faculty of Agriculture and Veterinary Medicine, Thamar University, \\ Dhamar, Yemen, ${ }^{2}$ Associate Professor, Dept. of Veterinary Medicine, Faculty of Agriculture and Veterinary Medicine, Thamar, \\ University, Dept. of Laboratory Sciences, Faculty of Medical Sciences, Al-Saeeda University, Dhamar, Yemen, \\ ${ }^{3}$ Assistant Professor of Physiology, HOD, Dept. of Veterinary Medicine, Faculty of Agriculture and Veterinary Medicine, \\ Thamar, University, Dhamar, Yemen.
}

\section{*Corresponding Authors:}

Email: qudariays@yahoo.com

Received: $14^{\text {th }}$ May, 2018

Accepted: $2^{\text {nd }}$ September, 2018

\begin{abstract}
Introduction: Brucellosis is one of the common zoonotic diseases that leading to the extensive economic losses throughout the world. Control and eradication of this disease depends mainly on the early detection.

Aims: The present work was achieved between March and September 2016 as a cross-sectional study to determine the seroprevalence of brucellosis in cattle.

Materials and Methods: Three hundred eighty four sera samples which including 359 females and 25 males were collected randomly from unvaccinated cattle, in twelve different regions at Dhamar governorate in Yemen. All sera samples screened for cattle brucellosis using RBT and the positive samples reconfirmed using I-ELISA. A structured questionnaire used to collect epidemiological data that analyzed using SAS program.

Results and Discussion: The sero-prevalence of cattle brucellosis was $0.26 \%$. No significant association $(P \leq 0.05)$ between prevalence of cattle brucellosis and region $(2.8 \%)$, age $(3.22 \%)$, sex $(0.27 \%)$ and breed $(0.26 \%)$ was determined.

Conclusion: Study findings showed a low prevalence of cattle brucellosis in Dhamar governorate. Although, the current work form a baseline data for more study of cattle brucellosis, and start point for its control in Yemen.
\end{abstract}

Keywords: Brucellosis, Cattle, Dhamar Governorate, RBT, I-ELISA, Sero-prevalence, Yemen.

\section{Introduction}

Brucellosis is considered one of the most common diseases worldwide, and form a major impact on human, livestock production and the economy. ${ }^{1}$ It's a bacterial infection caused by the Brucella genus that has a numerous species of small, non-spore forming, non-motile, gram-negative coccobacilli short rods that have been documented for a number of years., ${ }^{2,3}$ Brucella abortus is one of these species that discovered by the Danish who isolated the organism from aborted cows in $1897 .{ }^{4}$ Brucellosis in cattle is important due to its prevalent distribution and the public health hazard that it causes..$^{5-8}$ On the other hand, various of clinical findings have been described in infected cattle such as hygroma, orchitis, placenta retention, weak or still births and long calving intervals. ${ }^{9,10}$

Isolation and identification of Brucella is the best way for diagnosis of brucellosis infections. However, due to its expenses, difficulty of performance, and lack of sensitivity in which the isolating of bacteria not exceed $20 \%$ of the cases, the laboratory diagnosis of brucellosis is prepared chiefly by serological tests. ${ }^{11}$ Additionally, the epidemiological studies depends mainly on the serological tests to detect the prevalence of brucellosis that appears to be critical for its control. ${ }^{12}$ There are several serological tests for demonstrating that Brucella antibodies arise in serum. The frequently used tests are the Rose Bengal Test (RBT), antiglobulin (Coombs) test, serum agglutination test (SAT), 2-mercaptoethanol, rivanol, and the enzyme-linked immune sorbent assay (ELISA). ${ }^{13}$ ELISA is considered a better test in early detection of brucellosis infection. ${ }^{14}$ In cattle and other animals, indirect-ELISA has been developed in different parts of the world for diagnosis of brucellosis. ${ }^{15-18}$

In bovine brucellosis, the main reason for the spread of infection is the cattle that aborting in stable and farmyards. It's reported that abortion appears to be high among Brucella-infected cattle with three to four times than unexposed cattle. ${ }^{19,20}$ The main rout by which bovine brucellosis can be transmitted is the oral by ingestion of the contaminated food or water with secretions of infected animals, remains of aborted fetal, or by licking the genitals, secretions of vagina, aborted fetuses or the newborns from infected cattle. The artificial insemination by infected semen plays an important role in disease transmission. In general, transmission of bovine brucellosis by venereal rout is not epidemiologically important. ${ }^{21}$

The epidemiology of bovine brucellosis is changeable worldwide. It's described in nearly every one of countries where cattle are farmed, with some countries in central and north of Europe, Japan, America, Australia, Canada, and New Zealand that considered free from this disease..$^{21-23}$ On the other hand, the disease appears to be endemic in several countries in Africa, Middle East and Asia due to the 
weak of control programs or they principally do not have a massive impact in animal and human health. ${ }^{24,25}$ In some countries of Middle East such as Kingdome of Saudi Arabia and Oman, the prevalence of bovine brucellosis was estimated to be $3.6 \%$ and $3.3 \%$ respectively. In Yemen, brucellosis is considered one of the major disease problems that influence animal industry as well as human health so far. The existence of brucellosis already confirmed in local animals. The prevalence of bovine brucellosis was reported to be low $(0.06 \%)$ as compared to the other animals imported to Yemen from Somalia and other African countries. ${ }^{26}$ Dhamar governorate of Yemen is known to possess a high rate of the livestock. However, the problems of animal health such as bovine brucellosis in this region received less attention from researchers. Therefore, the present study aimed to the following objectives:

1. Detection of brucellosis in cattle using RBT as a screening test and using the I-ELISA to determine the sero-prevalence of brucellosis as a confirmatory test.

2. Determine some risk factors including age, sex, breed and region and their role in disease distribution.

\section{Materials and Methods}

Study Areas: The current work was conducted from March to September 2016 in twelve different districts in Dhamar Governorate and including: Al-Hada, Al Manar, Anss, Dawran Aness, Dhamar City, Jabal Alsharq, Jahran, Maghreb Anss, Mayfa'at Anss, Utmah, Wusab Al-Alee and Wusab Al-Safeel.

Study Population and Design: The cattle with age more than nine months were a population for studying the sero-prevalence of bovine brucellosis. Acrosssectional study designed with structured questionnaire to collect the epidemiological data of cattle that including: age, sex, breed and region. The sera samples were collected and subjected for screening using RBT in Department of Microbiology, Faculty of Agriculture and Veterinary Medicine, Thamar University, Dhamar Governorate, Yemen. Only positive samples were confirmed using I-ELISA in the Veterinary Central Lab., Sana'a Governorate of Yemen.

Samples Collection: Three hundred eighty four (384) of blood samples were collected randomly from unvaccinated individual cattle. Seven $\mathrm{ml}$ of blood was collected by plain vacutainer tubes from the jugular vein of each animal. Blood samples were left for half an hour at room temperature for separation of serum that stored at $-20^{\circ} \mathrm{C}$ till use.

\section{Serological Analysis}

Rose Bengal Test: The procedure of RBT was achieved according on the Manual of Standards for Diagnostic Tests and Vaccines. ${ }^{27}$ Serum samples and antigen (Dae Sung Microbiological lab, South Korea) were left at room temperature for one an hour prior to the start of the test. In general, any degree of visible agglutination was considered as a positive result, whereas the absence of agglutination was interpreted as a negative result.

Indirect-ELISA: All RBT positive samples reconfirmed using I-ELISA (Svanova Biotech AB, Uppsala, Sweden). I-ELISA was performed according on the manufacturer company.

\section{Statistical Analysis}

The questionnaire data was processed and statistically analyzed using SAS program 9.1.3 (2002). Differences among means were detected by chi-square $\left(\chi^{2}\right)$, and T-test. $P \leq 0.05$ was considered a significant.

\section{Results}

Overall Crude Sero-prevalence of Cattle Brucellosis: 384 serum samples collected randomly from cattle of twelve different districts in Dhamar governorate of Yemen. The prevalence of cattle brucellosis estimated to be $3.38 \%$ using RBT. Only positive samples subjected for further confirmation using I-ELISA. The prevalence was $0.26 \%$ as in table 1 .

Sero-prevalence of Cattle Brucellosis and Correlated with Sex: Cattle brucellosis detected only in females with prevalence estimated to be $0.27 \%$ using I-ELISA. The association between cattle brucellosis and sex was not statistically significant $\mathrm{p}=0.7916$ as in table 2.

Sero-prevalence of Cattle Brucellosis and Correlated with Age: Brucellosis infection of cattle detected mainly among young animals (1-4 years of age), where the prevalence reach to $7.69 \%$ using RBT and after the confirmation of positive samples by IELISA, the prevalence was $0.96 \%$ (one out of 104 samples). No infection determined in the other age groups using I-ELISA. The association between cattle brucellosis seropositivity and age was not statistically significant $\mathrm{p}=0.7225$ as in table 3 .

Sero-prevalence of Cattle Brucellosis and Correlated with Breed: The prevalence of cattle brucellosis among Zebu breed that forms the majority of study animals (381) was $3.14 \%$ using RBT. All positive samples reconfirmed using the I-ELISA and the prevalence determined as $0.26 \%$. Among Friesian breed, no infection detected using I-ELISA with no statistical significance between cattle brucellosis infection and breed $\mathrm{p}=0.9292$ as in table 4 .

Sero-prevalence of Cattle Brucellosis and Correlated with Regions: Brucellosis in cattle detected only in Dhamar city with prevalence $2.77 \%$ (one out of 36 samples). No positive reactions detected using I-ELISA in the other regions. The association between brucellosis infection and regions was not statistically significant $\mathrm{p}=0.7225$ as in table 5 . 
Table 1: Overall sero-prevalence of brucellosis in cattle based on RBT and I-ELISA

\begin{tabular}{|l|c|c|c|}
\hline $\begin{array}{c}\text { Total number of } \\
\text { sera tested }\end{array}$ & $\begin{array}{c}\text { Total number of } \\
\text { RBT positive } \\
\text { reactors (\%) }\end{array}$ & $\begin{array}{c}\text { Reconfirmation of RBT } \\
\text { positive reactors by I- } \\
\text { ELISA (\%) }\end{array}$ & $\begin{array}{c}\text { Overall sero-prevalence } \\
\text { based on I-ELISA (\%) }\end{array}$ \\
\hline 384 & $13(3.38)$ & $1(7.7)$ & 0.26 \\
\hline
\end{tabular}

Table 2: Sero-prevalence of brucellosis according on sex using RBT and I-ELISA

\begin{tabular}{|l|c|c|c|c|c|}
\hline $\begin{array}{c}\text { Sex of } \\
\text { animals }\end{array}$ & $\begin{array}{c}\text { Number } \\
\text { of sera } \\
\text { tested }\end{array}$ & $\begin{array}{c}\text { Number of } \\
\text { positive reactors } \\
\text { by RBT (\%) }\end{array}$ & $\begin{array}{c}\text { Reconfirmation of } \\
\text { RBT positive reactors } \\
\text { by I-ELISA (\%) }\end{array}$ & $\begin{array}{c}\text { Sero-prevalence } \\
\text { based on I-ELISA } \\
(\%)\end{array}$ & $\begin{array}{c}\boldsymbol{P} \text {-value } \\
(\boldsymbol{P} \leq \mathbf{0 . 0 5})\end{array}$ \\
\hline Male & 25 & $0(0)$ & $0(0)$ & 0 & 0.7916 \\
\hline Female & 359 & $13(3.62)$ & $1(7.7)$ & 0.27 & \\
\hline
\end{tabular}

Table 3: Sero-prevalence of brucellosis according on age using RBT and I-ELISA

\begin{tabular}{|c|c|c|c|c|c|}
\hline $\begin{array}{c}\text { Age of } \\
\text { animals } \\
\text { (years) }\end{array}$ & $\begin{array}{l}\text { Number of } \\
\text { sera tested }\end{array}$ & $\begin{array}{l}\text { Number of } \\
\text { positive } \\
\text { reactors by } \\
\text { RBT }(\%)\end{array}$ & $\begin{array}{l}\text { Reconfirmation of } \\
\text { RBT positive reactors } \\
\text { by I-ELISA }(\%)\end{array}$ & $\begin{array}{l}\text { Sero-prevalence } \\
\text { based on I- } \\
\text { ELISA }(\%)\end{array}$ & $\begin{array}{c}P \text {-value } \\
(P \leq 0.05)\end{array}$ \\
\hline $1-4$ & 104 & $8(7.69)$ & $1(12.5)$ & $1(0.96)$ & \multirow{4}{*}{0.7225} \\
\hline $5-9$ & 251 & $3(1.19)$ & 0 & 0 & \\
\hline$>10$ & 29 & $2(6.89)$ & 0 & 0 & \\
\hline Total & 384 & $13(3.38)$ & $1(7.69)$ & $1(0.26)$ & \\
\hline
\end{tabular}

Table 4: Sero-prevalence of brucellosis according on breed using RBT and I-ELISA

\begin{tabular}{|l|c|c|c|c|c|}
\hline $\begin{array}{c}\text { Breed of } \\
\text { animals }\end{array}$ & $\begin{array}{c}\text { Number } \\
\text { of sera } \\
\text { tested }\end{array}$ & $\begin{array}{c}\text { Number of } \\
\text { positive reactors } \\
\text { by RBT (\%) }\end{array}$ & $\begin{array}{c}\text { Reconfirmation of } \\
\text { RBT positive reactors } \\
\text { by I-ELISA (\%) }\end{array}$ & $\begin{array}{c}\text { Sero-prevalence } \\
\text { based on I-ELISA } \\
(\boldsymbol{\%})\end{array}$ & $\begin{array}{c}\boldsymbol{P} \text {-value } \\
(\boldsymbol{P} \leq \mathbf{0 . 0 5})\end{array}$ \\
\hline Zebu & 381 & $12(3.14)$ & $1(8.4)$ & 0.26 & 0.9292 \\
\hline Friesian & 3 & $1(33.4)$ & $0(0.0)$ & 0.0 & \\
\hline
\end{tabular}

Table 5: Sero-prevalence of brucellosis according on region using RBT and I-ELISA

\begin{tabular}{|l|c|c|c|c|c|}
\hline \multicolumn{1}{|c|}{ Regions } & $\begin{array}{c}\text { Number } \\
\text { of sera } \\
\text { tested }\end{array}$ & $\begin{array}{c}\text { Number of } \\
\text { positive } \\
\text { reactors by } \\
\text { RBT (\%) }\end{array}$ & $\begin{array}{c}\text { Reconfirmation of } \\
\text { RBT positive } \\
\text { reactors by I- } \\
\text { ELISA (\%) }\end{array}$ & $\begin{array}{c}\text { Sero- } \\
\text { prevalence } \\
\text { based on I- } \\
\text { ELISA (\%) }\end{array}$ & $\begin{array}{c}\boldsymbol{P} \text {-value } \\
(\boldsymbol{P} \leq \mathbf{0 . 0 5})\end{array}$ \\
\hline Dhamar city & 36 & $5(13.88)$ & $1(20.00)$ & 2.77 & \multirow{2}{*}{0.7225} \\
\hline Utmah & 38 & $2(5.26)$ & $0(0.0)$ & 0 & \\
\hline Jahran & 33 & $0(0.0)$ & $0(0.0)$ & 0 & \\
\hline Al-Hada & 30 & $1(3.33)$ & $0(0.0)$ & 0 \\
\hline Anss & 31 & $0(0.0)$ & $0(0.0)$ & 0 \\
\hline Maghirib Ans & 33 & $1(3.03)$ & $0(0.0)$ & 0 \\
\hline Mayfa'at Anss & 35 & $0(0.0)$ & $0(0.0)$ & 0 & \\
\hline Dawran Aness & 40 & $2(5.00)$ & $0(0.0)$ & 0 & \\
\hline Jabal Al-Sharq & 35 & $1(2.85)$ & $0(0.0)$ & 0 & \\
\hline Al Manar & 32 & $0(0.0)$ & $0(0.0)$ & 0 & \\
\hline Wusab Al-Alee & 21 & $0(0.0)$ & $0(0.0)$ & 0 & \\
\hline Wusab Al-Safeel & 20 & $1(5.00)$ & $0(0.0)$ & 0 & \\
\hline
\end{tabular}

\section{Discussion}

Brucellosis is considered one of the main zoonotic diseases that cause an extensive economic losses in animal production and several of the public health problems. ${ }^{28}$ Bovine brucellosis distributed in wide parts of the words ${ }^{29}$ and detection of the bovine brucellosis prevalence using the serological tests such as RBT and I-ELISA is essential to its control. ${ }^{30,31}$ Because I-ELISA appears to be unable to distinguish between the antibody response induced by vaccination with $B$. abortus strain 19 and natural infection with the organism, ${ }^{32}$ therefore all samples involved in the present work collected from individual unvaccinated animals. The present investigation showed that the overall sero-prevalence of brucellosis in cattle was $0.26 \%$ by I-ELISA. In fact, few studies performed regarding cattle brucellosis distribution in Yemen and 
particularly in Dhamar governorate. However, the current study finding was roughly agreement with a previous study on cattle, ${ }^{26}$ where the prevalence of brucellosis in cattle was $0.06 \%$. Reports about brucellosis sero-prevalence in cattle showed great inconsistencies. In $\operatorname{Iran},{ }^{33}$ the prevalence of cattle brucellosis $(0.85 \%)$ was close to our finding. In neighboring countries such as Oman, Saudi Arabia, Eretria and United Arab Emirates (UAE), the prevalence of brucellosis in cattle $(3.3 \%, 3.6 \%, 8.20 \%$ and $1.30 \%$ respectively) was fairly higher than our finding. $15,34,35$ The prevalence of cattle brucellosis in different parts of the word including Brazil, Libya, Egypt, Bangladesh, Nigeria, India and Uganda (2.9\%, $42.0 \%, 7.77 \%, 2.66 \%, 24.0 \%, 5.00 \%$ and $14.0 \%$ respectively) $)^{31,36-40}$ was elevated as compared to the study outcome.

Essentially, there are a several factors that may effect on disease prevalence and severity and including the breed, geographic setting, kind of diagnostic test, husbandry and environmental factors. ${ }^{41}$ In current study, all the animals were selected individually, and the low prevalence of disease may be attributed to the fact that rate of brucellosis infection among individual animals is lower than animals which life in herds..$^{21}$ On the other hand, its reported that brucellosis in cattle occurred particularly with high rate of prevalence in the tropical countries. ${ }^{29}$ Therefore the reason behind the low prevalence of cattle brucellosis in the present study perhaps the location and environmental condition of the study area that localized between 2400-2500 meters above sea level and characterized by drying and cooling climate.

The present investigation demonstrates that cattle brucellosis seropositivity by I-ELISA was not associated with region, sex, age and breed $(\mathrm{p}=0.7225$, $0.7916,0.7225$ and 0.9292 respectively). Our finding is in agreement with those reported in Nigeria ${ }^{42}$ and Ethiopia ${ }^{43}$ In addition, several studies in different parts of the worlds showed that no significant association between the prevalence of this disease and risk factors such as breed and age. ${ }^{38,41,44}$ In contrast, other studies showed that bovine brucellosis seropositivity was significantly associated with those risk factors. In India, age and breed showed significant $(\mathrm{p}<0.05)$ association with prevalence of brucellosis in bovine. ${ }^{45}$ In SouthWestern of Nigeria, sex showed significantly associated (OR: 2.5; 95\% CI:1.3-4.5) with seropositivity of brucellosis in cattle (OR:2.5; 95\% CI:1.3-4.5). ${ }^{46}$ However, this difference could be attributed to fundamental variations in route of transmission and related risk factors. In general, our finding showed that infection was detected only in Dhamar city, and this perhaps due to it situation that localized in the center of the study area. Dhamar city characterized by allot of animals that introduced to it from different neighboring districts and villages for sealing purposes in animals' market fairs and this may be play a role in disease distribution.

\section{Conclusion}

In general, the current situation of brucellosis in Yemen is far from unambiguously clear. Therefore, a series of objectives and comprehensive studies will be useful to get a clear picture about such infection. The prevalence of brucellosis in cattle in Dhamar governorate was very low $0.26 \%$ with no statistical differences among risk factors involved in this study. These findings represent a baseline data for further study of brucellosis infection and start point for its control.

\section{Acknowledgement}

The authors extend their appreciation to the Veterinary Central Lab., Sana'a Governorate; Department of Microbiology, Faculty of Agriculture and Veterinary Medicine, Thamar University for providing the necessary facilities to conduct the study.

\section{References}

1. OIE. Bovine brucellosis. In: Manual of standards for diagnostic tests and vaccines. 4th ed ed: OIE, Paris; 2000.

2. Baek B, Lim C, Rahman M, Kim C-H, Oluoch A, Kakoma I. Brucella abortus infection in indigenous Korean dogs. Canadian Journal of Veterinary Research. 2003;67(4):312.

3. Kakoma I, Oluoch A, Baek B, Rahman M, Matsuda K. More attention warranted on Brucella abortus in animals. Journal of the American Veterinary Medical Association. 2003;222(3):284.

4. Osman SZE. Seroprevlance, risk factors and economic effect of brucellosis in jebel aulia: Sudan University of Science and Technology; 2015.

5. Boschiroli M-L, Foulongne V, O'Callaghan D. Brucellosis: a worldwide zoonosis. Current opinion in microbiology. 2001;4(1):58-64.

6. Dobrean V, Opris A, Daraban S. An epidemiological and surveillance overview of brucellosis in Romania. Veterinary microbiology. 2002;90(1):157-63.

7. Refai M. Incidence and control of brucellosis in the Near East region. Veterinary microbiology. 2002;90(1):81-110.

8. (OIE) WOfAH. Bovine brucellosis. In Manual of Diagnostic Tests and Vaccines for Terrestrial Animals. 5 ed: OIE, Paris; 2004.

9. Blood D, Radostits O. Veterinary Medicine. 7 ed: Bailliere Tindall, London; 1989.

10. Musa M, Jahans K, Fadalla M. Brucella biovars isolated from nomadic cattle in the southern Darfur Province of Western Sudan. Journal of Comparative Pathology. 1990;102(1):49-54.

11. Renner ED. Brucellosis. Clin Microbiol Newsl1979.

12. Erdenebaatar J, Bayarsaikhan B, Yondondorj A, Watarai M, Shirahata T, Jargalsaikhan E, et al. Epidemiological and serological survey of brucellosis in Mongolia by ELISA using sarcosine extracts. Microbiology and Immunology. 2004;48(8):571-7.

13. Morgan W. Brucella abortus. Handbuch der bakteriellen Infektionen bei Tieren Jena. 1982:53-213.

14. Rojas X, Alonso O. ELISAs for the diagnosis and epidemiology of brucella abortus infection in cattle in Chile. Arch Vet XXVII N ${ }^{\mathrm{a}}$ Extraordinario. 1995:45-50. 
15. Omer M, Skjerve E, MacMillan A, Woldehiwet Z. Comparison of three serological tests in the diagnosis of Brucella infection in unvaccinated cattle in Eritrea. Preventive veterinary medicine. 2001:48(3):215-22.

16. Dajer Abimerhi AF, Gutierrez Ruiz EJ, Zapata Vilallobos DdlM. Use of an enzyme-linked immunosorbent essay and the rivanol agglutination test for the diagnosis of bovine brucelosis in Yucatan State, Mexico. Veterinaria Mexico (Mexico). 1998

17. Molnár E, Molnár L, Vale W. Value of different serological tests in the diagnosis of bovine brucellosis in the Amazonian region. Acta Veterinaria Hungarica. 1997;46(2):199-210.

18. Romero C, Pardo M, Grillo MJ, Diaz R, Blasco J, LopezGoñi I. Evaluation of PCR and indirect enzyme-linked immunosorbent assay on milk samples for diagnosis of brucellosis in dairy cattle. Journal of clinical microbiology. 1995;33(12):3198-200.

19. Muma J, Samui K, Oloya J, Munyeme M, Skjerve E. Risk factors for brucellosis in indigenous cattle reared in livestock-wildlife interface areas of Zambia. Preventive veterinary medicine. 2007;80(4):306-17.

20. Schelling E, Diguimbaye C, Daoud S, Nicolet J, Boerlin $\mathrm{P}$, Tanner M, et al. Brucellosis and Q-fever seroprevalences of nomadic pastoralists and their livestock in Chad. Preventive veterinary medicine. 2003;61(4):279-93.

21. Aparicio ED. Epidemiology of brucellosis in domestic animals caused by Brucella melitensis, Brucella suis and Brucella abortus. Rev sci tech Off int Epiz. 2013;32(1):5360.

22. SANCO. Relazione suun audit condotto in Italia dal 7 al 15 ottobre 2013 al fine di valutare i programmi di eradicazione della brucellosi di bovini, ovini e caprini. 2013.

23. Greece. Brucellosis program in 2011. Ministry of Rural Development and Food; 2012.

24. McDermott J, Grace D, Zinsstag J. Economics of brucellosis impact and control in low-income countries. Rev Sci Tech. 2013;32(1):249-61.

25. Rich KM, Perry BD. The economic and poverty impacts of animal diseases in developing countries: new roles, new demands for economics and epidemiology. Preventive veterinary medicine. 2011;101(3):133-47.

26. Al Shamahy H. Seropositivity for brucellosis in a sample of animals in the Republic of Yemen. 1999.

27. OIE. Manual of Standards for Diagnostic Tests and Vaccines. 6 ed: OIE, Paris, France; 2008.

28. Neta AVC, Mol JP, Xavier MN, Paixão TA, Lage AP, Santos RL. Pathogenesis of bovine brucellosis. The Veterinary Journal. 2010;184(2):146-55.

29. JANSEN S, Muller W. The worldwide distribution of brucellosis-epidemiological tendencies from 1967-1979. Tierarztliche Umschau. 1982;37(8):564-70.

30. Barroso GP, Rodríguez-Contreras PR, Gil EB, Maldonado MA, Guijarro HG, Martín SA, et al. Study of 1,595 brucellosis cases in the Almeria province (19721998) based on epidemiological data from disease reporting. Revista clinica espanola. 2002;202(11):577-82.

31. Rahman M, Faruk M, Her M, Kim J, Kang S, Jung S Prevalence of brucellosis in ruminants in Bangladesh. Veterinarni Medicina. 2011;56(8):379-85.

32. Saravi MA. Vet. Immunol. Immunopathol 1995.

33. Zowghi E, Ebadi A, Mohseni B. Isolation of Brucella organisms from the milk of seronegative cows. Revue scientifique et technique (International Office of Epizootics). 1990;9(4):1175-8.
34. El Tahir Y, Nair RR. Prevalence of brucellosis in the Sultanate of Oman with reference to some Middle East countries. Vet Res. 2011;4:71-6.

35. Afzal M, Sakkir M. Survey of antibodies against various infectious disease agents in racing camels in Abu Dhabi, United Arab Emirates. Revue scientifique et technique (International Office of Epizootics). 1994;13(3):787-92.

36. Borba M, Stevenson M, Goncalves V, Neto JF, Ferreira F, Amaku M, et al. Prevalence and risk-mapping of bovine brucellosis in Maranhão State, Brazil. Preventive veterinary medicine. 2013;110(2):169-76.

37. Ahmed M, Elmeshri S, Abuzweda A, Blauo M, Abouzeed Y, Ibrahim A, et al. Seroprevalence of brucellosis in animals and human populations in the western mountains region in Libya, December 2006January 2008. Euro Surveill. 2010;15(30):19625-8.

38. Mai HM, Irons PC, Kabir J, Thompson PN. A large seroprevalence survey of brucellosis in cattle herds under diverse production systems in northern Nigeria. $B M C$ veterinary research. 2012;8(1):144.

39. Trangadia B, Rana SK, Mukherjee F, Srinivasan VA. Prevalence of brucellosis and infectious bovine rhinotracheitis in organized dairy farms in India. Tropical animal health and production. 2010;42(2):203-7.

40. Miller R, Nakavuma J, Ssajjakambwe P, Vudriko P, Musisi N, Kaneene J. The prevalence of brucellosis in cattle, goats and humans in rural Uganda: a comparative study. Transboundary and emerging diseases. 2016;63(6).

41. Amin KM, Rahman MB, Rahman MS, cheol Han J, ho Park J, seok Chae J. Prevalence of Brucella antibodies in sera of cows in Bangladesh. Journal of Veterinary Science. 2005;6(3):223-6.

42. Adamu S, Atsanda N, Tijjani A, Usur A, Sule A, Gulani I. Epidemiological study of bovine brucellosis in three senatorial zones of Bauchi State, Nigeria. Veterinary world. 2016;9(1):48.

43. Bashitu L, Afera B, Tuli G, Aklilu F. Sero-prevalence study of bovine brucellosis and its associated risk factors in Debrebirhan and Ambo towns. Advances in Dairy Research. 2015:1-4.

44. Nahar A, Ahmed M. Sero-prevalence study of brucellosis in cattle and contact human in Mymensingh district. Bangladesh Journal of Veterinary Medicine. 2009;7(1):269-74.

45. Patel M, Patel P, Prajapati M, Kanani A, Tyagi K, Fulsoundar A. Prevalence and risk factor's analysis of bovine brucellosis in peri-urban areas under intensive system of production in Gujarat, India. Veterinary world. 2014;7(7).

46. Ayoola MC, Akinseye VO, Cadmus E, Awosanya E, Popoola OA, Akinyemi OO, et al. Prevalence of bovine brucellosis in slaughtered cattle and barriers to better protection of abattoir workers in Ibadan, South-Western Nigeria. The Pan African Medical Journal. 2017;28.

How to cite this article: Al-Qudari AY, Al-
Garadi MA, Al-Monifi FA. Sero-prevalence of
brucellosis in cattle at Dhamar governorate,
Yemen. Indian J Microbiol Res. 2018;5(3):326-
330 .

